\title{
Zur Ikonographie des heiligen Spyrid.
}

Der hl Spyridon war Bischof ron Trimithus auf Cypern. Zur Zeit des Kaisers Maximian wurde ihm das rechte Ange ausgerissen und ihm das linke Bein verletzt. Nachber wurde er zur Arbeit in den Bergwerken verurteilt. Später nahm er am Konzil in Nikaia toil und bekehrte dort einen heidnischen Philosophen. Auch an dem Konzil von Sardica nahm or nach Angabo des hl Athanarios teil. Fs wird ihm die Gabe der Prophezeing und der Wunder nachgertihmt. Doch ist es wohl nicht notwrondig, hieranf näber einzngehen, da sie für die späteren Ausführungen nicht viel Bedeutung haben, und dio Wunder auch im Athosmalbuch zum Teil aufgefuhrt werden. Binmal hat er einen überschwemmiten Bach durch seinen Befehl aufgehalten. Als Schafhirt - denn aus Demat soll er als Bischof. Schafe gehütet haben - hat er Räuber in runderbarer Weise gefesselt. Den Kaiser Konstantius soll er in Antiochia geheilt haben. Nachdem er seine Diözese in wunderbarer Weise geleitet hatte, starb er in hohem Alter. Sein Leichnam wurde später nach Korfu tbergeftahrt und wird noch dort aufbewahrt.

Der Heilige wird am meisten dort und im Qebiete des Adriatischen Meeres verehrt. Sehr verehrt ist er auch in Mesolungion, im Piräus nnd in Athen. Im Piräus war während dêr Türkenzeit ein berïhmtes Kloster des Heiligen. Von dort ist der Kult nach Athen gekommen, wo der Name sehr gebräuchlich ist. (Mitteilung von Professor Lampros durch Professor Dörpfeld.) Dargestellt wird er meist als Bischof in voller Pontifikalkleidung. So beschreibt ihn auch das Malerbuch und fügt hinzu, daB er einen gespaltenen Bart trage. Auf einer Ikon, Maria mit mehreren Heiligen, in meinem Besitz, ist er so dargestellt, nur daB er keinen gespaltenen Bart, sondern einen-vollen hat. In der linken Hand trägt er ein Buch. Mit der rechten segnet er.

Dagegen entsprechen zwei Kupferstiche, die ich vom Athos habe, ganz der Beschreibung des Malerbuches. Auf ihnen ist er mit den heiligen Modestos und Ignatios dargestellt. $\mathrm{Ob}$ er zu diesen besondere Beziehungen hat, kann ich nicht feststellen. Ebenso ist er mit ver- 
schiedenen Heiligen an der Ikonostase in San Giorgio dei Greci in Venedig dargestellt.

Man ist versucht, die 'Kopfbedeckung, die der Heilige trägt, als eine Mitra zu bezeichnen und daraus Schlthsse auf das Alter der Mitra in der griochischen Kircho zu ziehen. Denn in dem Menologiun des Kaimars Resilojos H im Vatikan ist or schon so dargestellt. Dem ist

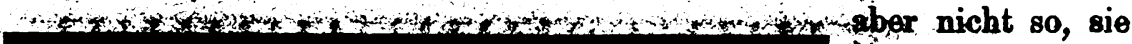

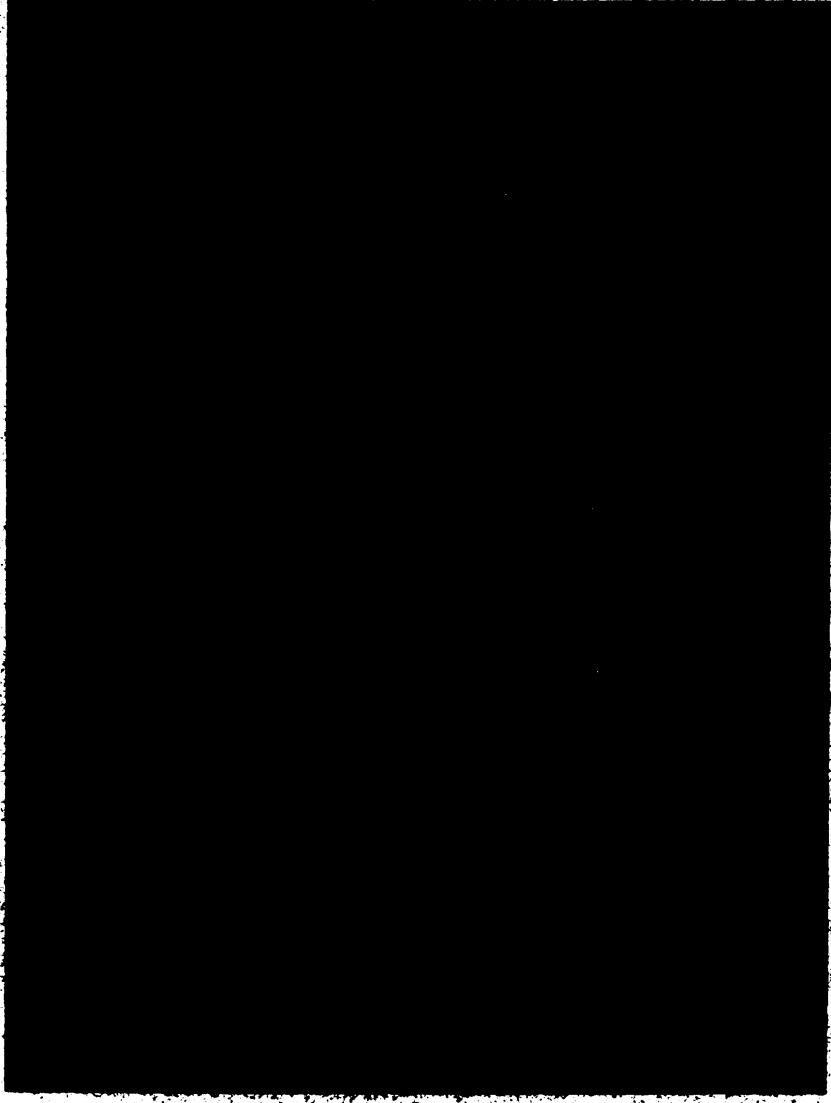

bipdeutet hier eine Hirtenmütze; rgl. Braun, Liturgische Gewandung des Okzidents und Orients, S. 490. Auf seine Hirtentätigkeit habe ich schon oben verwiesen. Auf der Miniatur hält er das Buch mit beiden Händen. Neben ihm ist ein WeihrauchfaB, dessen Bedentung mir nicht klar ist. Auf manchen Darstellungen sitzt der Heilige anf einen Throne, umgeben von kleineren Szenen aus seinem Leben. Noch eine andere zeigt ihn mit Mitra und Stab. In der linken Hind halt or die schlonge, die or in Gold verwandelt hat, um don ror ihwa Krioenden zu anterstatzen. Die zuletat enwönten schoinen Vonetia or Kupforstiche zu sein, die sich an byzantínische Vortilder anschllaben. So schliebe ich ous Skizzon, die mir ein Bekannter in Paris noch denselben gemacht hat Die Darstellung des Heiligen mit den Szonon seines Lebens findet sich af einem Bilío im Museo civico in Venedig, das dex Priester Emanule Zane de Rotimo gemalt hat. Die Darstellung des Wunders mit der 
Schlange fand ich auch auf einem kleinen Buchsbaumrelief im Musée de Cluny.

Viel merkwürdiger ist'aber die folgende Darstellung, die sich auf einigen Ikonen befindet. Zwei davon sind in meinem Besitz. Die größere dieser beiden (s. Abb. 1) habe ich bei einem Antiquar in Ragasa gekauft. Der Heilige, ähnlich wie ein griechischer Mönch gekleidet, steht in einer Art Tabernakel oder Baumstamm. Vor ihm ist ein Buchpult. Über dem Tabernakel ist ein Baldachin angebracht. Unten sieht man eine Renaissanceballustrade.

Rechts und links stehen auf Wolken zwei Engel mit Kandelabern. Unter dem rechten Engel ist ein Wappen. Oben schweben zwei Engel mit Spruchbändern, die folgende Inschrift zeigen:

Salve humilitatis - exemplum.

Salve virtutis exemplum.

Die kleinere Ikon (s. Abb. 2)

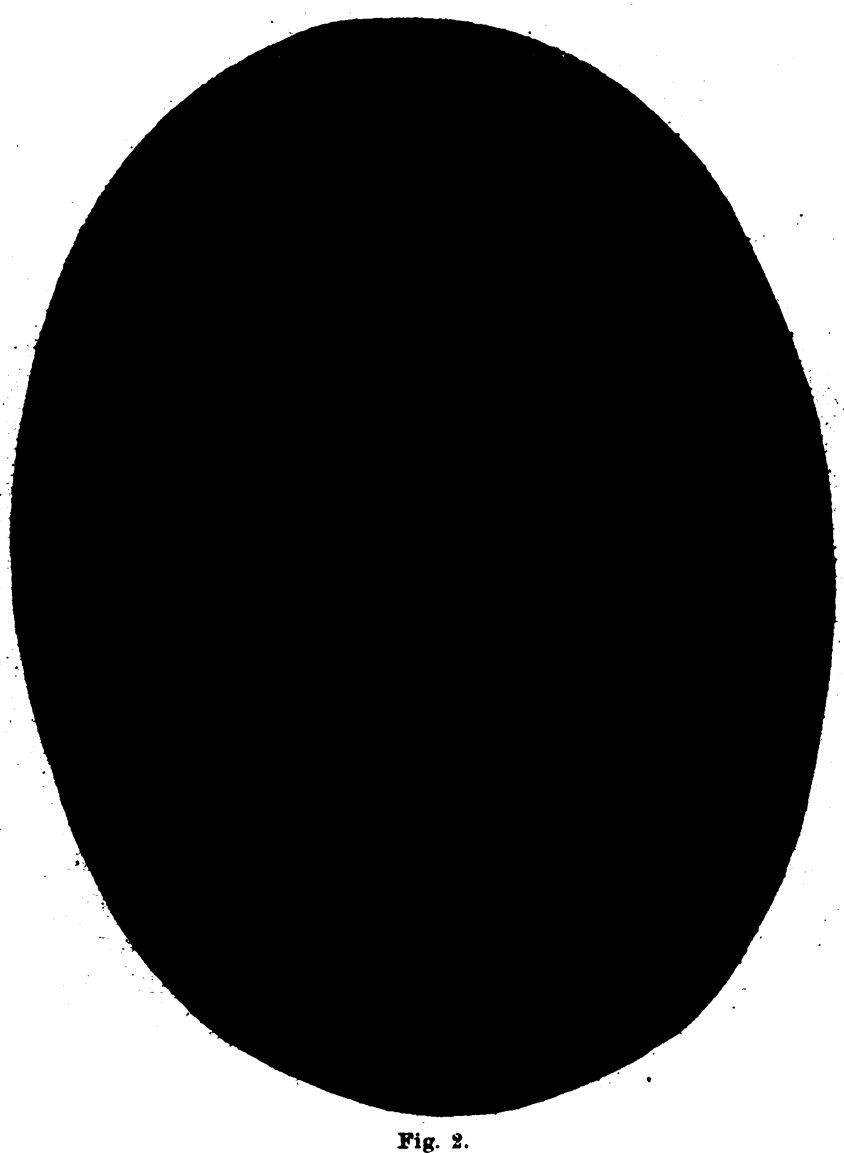
habe ich in Cannes gekauft. Hier könnte man versucht sein, anzunehmen, daB der Heilige sich in einem stehenden Sarge befände, wenn nicht ein Bücherpult davor wäre. Auch hier ist ein Baldachin, aber etwas anders. Die Ballustrade ist massiver. Zum Heiligen fuhren Stufen hinauf. Engel fehlen ganz. Die Inschrift lautet:

Reliquia di San Spiridione.

Eine dritte Ikon ist mir nur durch eine Photographie zugänglich, die mir Monsignore Bulić hat anfertigen lassen. Das Bild beñndet 
sich in der Kirche in Vranzie bei Spalato. Es entspricht in der Hauptsache dem zuerst genannten. Die Engel sind durch Buchstaben als $M\left(\iota \chi \alpha \eta^{\prime} \lambda\right)$ und $\Gamma\left(\alpha \beta \rho \iota \eta^{\prime} \lambda\right)$ bezeichnet. Die beiden oberen Engel

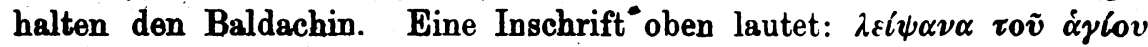

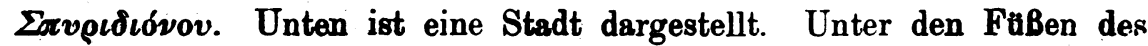
Heiligen ist ein Wappen. Anf einer Schleife steht: Divocione dal Nobss Co. Constantin della Decims. Nach der Meinung von Msgr. Bulié wäre das Bild darnach das Geochenk eines Zehntgrafen in Spalato, namens Konstantin, an die Kirche. In Venedig habe ich fünf solche Ikonen bei Antiquaren gefunden. Vier von ihnen haben griechische Inschriften und keine Engel. Bei einem sind Kandelaber zu sehen. Bei dem fünften ist die Inschrift italienisch, die Darstellung die gleiche. Erst schien es mir, dab die Darstellung auf San Giorgio dei Greci in Venedig zurückginge. Das hat sich aber bei genauer Untersuchung der dort befindlichen Bílder als falsch erwiesen. Auch eine Erkundigung beim Küster ergab nichts. Die Darstellung geht deshalb wohl eher auf Korfu zurück, wenn auch wohl die meisten Bilder in Venedig gefertigt sind.

Was bedeutet nun diese Darstellung? Vielleicht den Heiligen im Sarg? Ist es nur eine Reliquie, worauf die Worte Reliquia, $\lambda \varepsilon l \psi \alpha \nu \alpha$ deuten? Nach einer Mitteilung von Msgr. Bulić erklärt sich das dalmatinische Landvolk die Darstellung dahin, daB sich der Heilige einst in dem Stamme eines Olivenbaumes verborgen habe. Er wind deshalb als mächtiger Schutzheiliger der Ölbäume (auch bei den Katholiken) gefeiert und längs der dalmatinischen Küste verehrt. In Griechenland ist ron dieser Deutung gar nichts bekannt, wie mir Lampros durch Dörpfeld mitteilt. Nach Erkundigangen, die ich in Venedig eingezogen habe, wurde der hl Spiridon besonders von den Fischern von Chioggia verehrt. In Jedom Schiffe befand sich ein solches Bild, wie ich sie beschrieben habe. Darnach schoint es mehr, daB es die mumiflierte Leiche des Heiligen darstellt. Für diese Deutung möchte ich mich als die wahrscheinlichste aussprechen. Trotzdem wäre ich dankbar, wenn sich noch endere dieser Frage annehmen wollten. Denn sie hat nicht bloB ikonographisches, sondern auch volkskundliches Interesse.

Dresden.

Johanu Georg, Herzog zu Sachsen. 